\section{The Interpreters at the IRB}

\section{by Alex Zisman}

Refugee claimants being processed in Canada have a right to use interpreters. By faithfully reproducing in the target language what is said in the source language, the latter make it possible for claimants, panel members, counsel, refugee hearing officers (RHOs) or case officers at the Immigration and Refugee Board of Canada (IRB) hearings to properly communicate with each other. When interpreters are required, the accuracy and fairness of the proceedings hinge substantially upon their performance.

Interpreting demands much more than the mere display of fluency or proficiency in a given set of languages. Based on a culturallyentrenched search of equivalent meanings, interpreting requires a comprehensive grasp of context, a familiarity with backgrounds, permeated by social, historical, economic and geographic clues and references.

Not unlike sharpshooters, interpreters must be precise under stress or pressure. Mental agility, discipline and endurance, together with emotional stability, are also necessary attributes.

From its very inception the IRB expressed a desire to hire the best available interpreters on a freelance basis. But, after tapping resources through traditional grapevines (federal or provincial channels, translation agencies, university and individual contacts) the IRB found itself having to recruit candidates without a formally regulated screening procedure in place.

With no specific guidelines to properly appraise candidates before hiring them, rigorous testing was largely spared. Experienced candidates were usually hired by the regional offices once they showed familiarity with basic procedures. Novices were encouraged to attend hearings as observers to familiarize themselves with the job and see whether they could cope with its requirements. In Calgary, candidates were given a small glossary compiled by the regional office and were hired only after assuring officials that they could confidently translate verbatim the terminology listed. Other offices either had no glossaries ready or were waiting for official approval before handing them over to interpreters. In the latter cases the interpreters were merely briefed on procedures before being sent to work.

Although there has obviously been a need for further and ongoing technical training of interpreters at the IRB, this has not yet been forthcoming, in sharp contrast with the meticulous and periodic preparation provided to panel members and RHOs alike.

Interpreters have only been formally instructed to abide by specific and clearly defined rules of professional conduct. They must remain impartial, keep a polite distance from all those involved in the hearings and avoid conflicts of interest. To a certain degree, these measures have a specific purpose. They serve as precautionary and even preventive devioes designed to minimize the possibilities of a mistrial.

While the IRB readily monitors the behaviour of interpreters at its premises both during and outside the hearings, a dearth of specific guidelines and evaluating mechanisms leaves each of its regional offices free to compile its appraisals as each deems fit.

Toronto and Vancouver rely on information provided mainly by panel members' and, to a lesser degree, by RHOs and case officers, to rate and even informally rank interpreters. This ranking can ultimately help determine whether and how much a given interpreter is going to be used.

Calgary and Winnipeg also get most of their feedback from these sources. They count on the information to determine the general competence of an interpreter, but prefer not to adhere to a ranking system.

Montreal is the only regional office with a genuine need for people capable of interpreting into both official languages, since French and English are substantially used there on a daily basis. This office relies on proven interpreters to observe the performance of new interpreters during the hearings. Once interpreters are considered reliable they are used as part of a pool. If there is a surplus of qualified interpreters in a given language, they are put on rotation in a manner which is clearly non-discriminatory.

The differences in evaluation pose some problems, particularly when the sources being tapped are not properly qualified to provide a full assessment. The proficiency of an interpreter can only be adequately rated if an evaluator has a total mastery of the language used by the claimant. This mastery alone places the evaluator in a position to judge how competent the overall performance of the interpreter really is. Input devoid of context and of sufficient points of reference can undermine the accuracy of an evaluation.

Some input received about the interpreters by the regional offices tends to be of an incidental rather than global nature. Comments emanating from lawyers acting as counsel provide a good example of this. Since their main concern is that the performance of the interpreters should not prove detrimental to their clients' claims, their comments respond mostly to policing needs and are usually limited to challenging rather than praising the competence or trustworthiness of interpreters.

Although most lawyers, if pressed, would acknowledge and even pay tribute to the fine skills of many interpreters hired by the IRB, in some cases they would still insist on bringing their own observers along to corroborate independently the accuracy of the interpretation.

Interpreters, for their part, can do little to contest the method in which they are being assessed. Still officially untested and unaccredit- ed, they have been given little opportunity, particularly in a large regional office such as Toronto, to have much say in how they should contribute to the hearings. As a result of their present lack of empowerment, interpreters in general remain structurally alienated and tacitly constrained within the participatory dimension of the refugee determination process. In spite of the congenial atmosphere usually prevalent during the hearings, interpreters in most cases feel reduced to an essentially passive, isolated and slightly dehumanized technical function. Some minor aspects also make them feel relegated to the sidelines. For example, they are not provided with any prior information about the cases and have no automatic access to documentary evidence presented during the hearings, as panel members, counsel and RHOs or case officers do.

The IRB is already considering some steps to remedy this situation. In future, written and oral exams will be used as tools to screen, hire and grade the interpreters.

Other measures could also prove helpful.

Interpreters should be able to contribute to define the course and parameters of their position within the IRB. They should be consulted more often about their views and be encouraged to appraise their performances. A move in this direction can already be perceived in some regional offices. A constructive dialogue would only help improve and enhance the contribution of interpreters at the hearings, as would a systematic training on an ongoing basis.

As part of this dialogue interpreters should also be involved in the collective development of specialized glossaries. Their participation in task forces or working groups in charge of the preparation, updating and improvement of terminologies could prove invaluable.

Some specific concerns regarding access should also be resolved. Interpreters should be allowed prior access to non-confidential information about the cases such as the country of origin of the claimants. This would not only contribute to define in advance a context, but will also provide some guidance to interpreters who have to deal on a regular basis with claimants coming from more than one country.

They should also have at least temporary access to documents quoted during the actual hearings. This would ensure the completion of translations in a more expedient and less stressful manner.

When implemented, these improvements would certainly contribute to turn a potentially rewarding job into one which would also be more stimulating and meaningful.

Alex Zisman is the Executioe Editor of Refuge. He is also a vice-president of the Court Interpreters' Association of Ontario and has worked sporadically as an interpreter at the IRB since its inception. The views expressed in this article are his own and do not necessarily reflect the views or position of the IRB. 